\section{POS0241 VALIDATION OF THE ANKYLOSING SPONDYLITIS DISEASE ACTIVITY SCORE WITH A QUICK QUANTITATIVE C-REACTIVE PROTEIN ASSAY (ASDAS-QCRP) IN PATIENTS WITH AXIAL SPONDYLOARTHRITIS (AXSPA): A PROSPECTIVE, NATIONAL, MULTICENTER STUDY}

F. Proft ${ }^{1}$, J. Schally ${ }^{1}$, H. C. Brandt' ${ }^{2}$, J. Brandt-Juergens ${ }^{3}$, G. R. Burmester ${ }^{4}$, H. Haibel ${ }^{1}$, H. Käding ${ }^{1}$, K. Karberg ${ }^{2}$, S. Lüders ${ }^{1}$, B. Muche ${ }^{1}$, M. Protopopov ${ }^{1}$, J. Rademacher ${ }^{1}$, V. Rios Rodriguez ${ }^{1}$, M. Torgutalp ${ }^{1}$, M. Verba ${ }^{1}$, S. Zinke ${ }^{5}$, D. Poddubnyy ${ }^{1} .{ }^{1}$ Charité - Universitätsmedizin Berlin, Division of Gastroenterology, Infectiology and Rheumatology, Campus Benjamin Franklin, Berlin, Germany; ${ }^{2}$ Praxis für Rheumatologie und Innere Medizin, Praxis für Rheumatologie und Innere Medizin, Berlin, Germany; ${ }^{3}$ Rheumatologische Schwerpunktpraxis, Rheumatologische Schwerpunktpraxis, Berlin, Germany; ${ }^{4}$ Charité - Universitätsmedizin Berlin, Department of Rheumatology and Clinical Immunology, Berlin, Germany; ${ }^{5}$ Rheumapraxis Berlin, Rheumapraxis Berlin, Berlin, Germany

Background: According to international recommendations, the Ankylosing Spondylitis Disease Activity Score (ASDAS) is the preferred score for assessing disease activity in axial spondyloarthritis (axSpA) [1]. However, routine determination of C-reactive protein (CRP) to calculate ASDAS values takes hours to days. This limits the use of ASDAS in clinical routine and clinical trials and hinders the implementation of treat-to-target approaches in axSpA. Whereas quick quantitative CRP (qCRP) tests allow CRP assessment within a few minutes. In a pilot project the performance of qCRP-based ASDAS assessment (ASDASqCRP) was already investigated in a single center study of 50 newly diagnosed, bDMARD-naïve axSpA patients with promising results [2].

Objectives: To validate the ASDAS-qCRP in a prospective, multicenter study of axSpA patients in a typical axSpA cohort with an appropriate sample size.

Methods: The study was conducted in five centers in Germany. Consecutive adult ( $\geq 18$ years) axSpA patients were included. In addition to a rheumatological assessment, including patient reported outcomes (PROs), routine CRP and erythrocyte sedimentation rate (ESR) were measured in the local labs. Additionally, a qCRP testing with the "QuikRead go instrument" (Aidian Oy, Finland) was performed at the study center (measurement range $0.5-200 \mathrm{mg} / \mathrm{l}$ for hematocrit concentrations of $40-45 \%$ ). Statistical analysis included descriptive statistics, cross tabulation and weighted Cohen's kappa comparing disease activity categories, Bland-Altman plots and intraclass correlation coefficient (ICC) for ASDAS-CRP and ASDAS-qCRP. Results: In this study 251 axSpA patients were included between January and September 2020 (mean age: 38.4 years; mean disease duration: 6.2 years, 159 patients $(63.3 \%)$ were male, $211(84.1 \%)$ HLA-B27 positive and 195 (77.7\%) were classified as radiographic axSpA). 143 patients $(57.0 \%)$ were treated with bDMARDs. CRP and qCRP showed mean values of 2.12 and $2.17 \mathrm{mg} / \mathrm{l}$, respectively. With the ASDASqCRP, 242 patients (96.4\%) were assigned to the same disease activity category as compared to the ASDAS based on the conventional lab CRP measurement (Table 1). Weighted Cohen's kappa was 0.966 (95\%Cl: 0.943; 0.988). ICC for ASDAS-CRPand ASDAS-qCRP-values was $0.997(95 \% \mathrm{Cl}$ : 0.994; 0.999). The agreement of ASDAS-qCRP and ASDAS-CRP is shown in a Bland-Altman plot (Figure 1).

Conclusion: The ASDAS-qCRP and ASDAS-CRP showed an almost perfect agreement on the assignment to disease activity categories (96\%) with the important advantage of time. With ASDAS-qCRP, rheumatologists could base their clinical decision-making on a disease activity measurement by using a composite score immediately. ASDAS-qCRP, therefore, can be integrated in clinical routine and clinical trials in the future and may facilitate implementation of the treat-to-target concept in axial SpA.

REFERENCES:

[1] Smolen JS, et al. Ann Rheum Dis. 2018 Jan; 77(1):3-17.

[2] Proft $F$, et al. Joint Bone Spine. 2019 Jul 29.

Table 1. Disease activity categories by ASDAS-qCRP vs. ASDAS-CRP

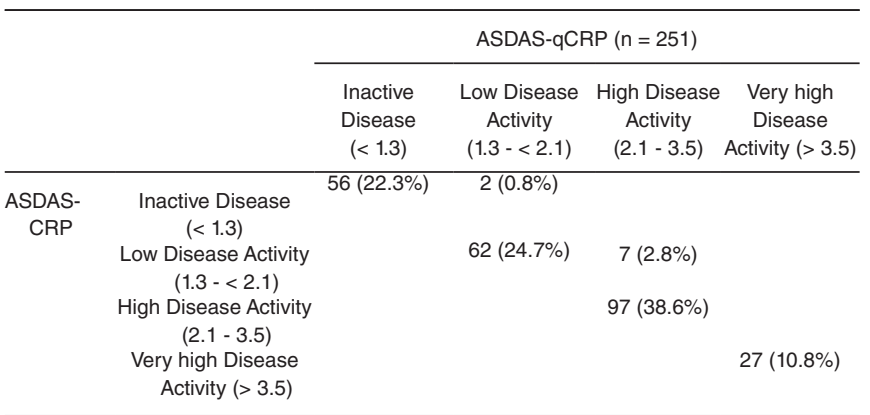

The fields highlighted in red indicate that disease activity categories do not match.ASDAS = Ankylosing Spondylitis Disease Activity Score, $\mathrm{CRP}=\mathrm{C}$-reactive protein, qCRP $=$ quick quantitative CRP

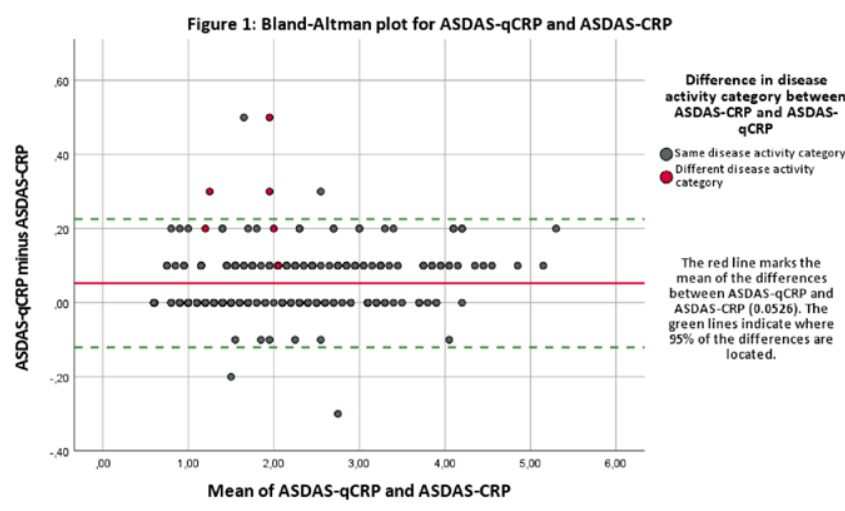

Figure 1. Bland-Altman plot for ASDAS-qCRP and ASDAS-CRP

Acknowledgements: The authors would like to deeply thank Braun T, Doerwald C, Deter N, Höppner C, Lackinger J, Lorenz C, Lunkwitz K, Mandt B, Sron S and Zernicke $\mathrm{J}$ for their practical support and coordinating the study.

Funding statement: The AQUA study was supported by an unrestricted research grant from Novartis. Testing kits were provided free of charge from Aidian Oy, Finland.

Disclosure of Interests: None declared

DOI: 10.1136/annrheumdis-2021-eular.2352

\section{POS0242 \\ ROLE OF HLA-B27 CARRIERSHIP IN PERIPHERAL SPONDYLOARTHRITIS: DATA FROM ASAS PERSPA STUDY}

M. Arévalo $^{1}$, C. López-Medina ${ }^{2}$, V. Navarro-Compán ${ }^{3}$, M. Moreno ${ }^{1}$, M. Llop Vilaltella $^{1}$, J. Calvet ${ }^{1}$, J. Gratacos-Masmitja ${ }^{1}$, M. Dougados ${ }^{4}$ on behalf of ASAS group. ${ }^{1}$ Hospital Parc Taulí I3PT, Rheumatology, Sabadell, Spain; ${ }^{2}$ Hospital Universitario Reina Sofía/IMIBIC/Universidad de Córdoba, Rheumatology, Cordoba, Spain; ${ }^{3}$ Hospital Universitario la Paz, IdiPaz, Rheumatology, Madrid, Spain; ${ }^{4}$ Hôpital Cochin, Rheumatology, Paris, France

Background: HLA-B27 is well known for its role in conferring susceptibility to spondyloarthritis (SpA), and several studies evaluating its association to axial SpA phenotype have been published. However, there is few evidence about its influence in patients affected with peripheral SpA (pSpA). In this sense we find ASAS perSpA registry suitable for this purpose.

Objectives: To identify phenotypical differences in $\mathrm{pSpA}$ patients regarding HLAB27 status.

Methods: Data from all patients fulfilling ASAS pSpA criteria with HLA-B27-testing result available included in the ASAS perSpA study were used for this analysis. Socio-demographic and disease characteristics were collected. A descriptive and comparative analysis was performed between HLA-B27 positive and negative patients, using a simple logistic regression for all variables to assess their association to HLA-B27 positivity. Results were considered significant when $p$ $<0.05$. A multivariate model was also performed including significant $(p<0.1)$ and the most relevant clinical variables in agreement of medical criteria.

Results: Among the 4465 patients included in the registry, 555 fulfilled ASAS pSpA criteria and of them 286 had the HLA-B27 typing available. HLA-B27 was positive in 118 (41.3\%) and negative in 168 (58.7\%). Results are listed in Table 1. No differences were observed for gender distribution (males $55.1 \%$ in HLA-B27 positive vs $49.4 \%$ in HLA-B27 negatives). HLA-B27 positive patients were significantly younger, presented a younger disease onset, had significantly higher prior axial involvement, radiographic sacroiliitis and higher root joint involvement. On the other hand, HLA-B27 negative patients showed longer disease duration with a higher diagnosis delay. Around half of the patients in both groups showed a mono or oligoarticular pattern without differences regarding HLA-B27 status, however, psoriatic arthritis ( $\mathrm{PSA}$ ) and peripheral joint damage was significantly higher in HLA-B27 negative patients. Also psoriasis and inflammatory bowel disease (IBD) were more frequent in HLA-B27 negative patients compared to positive ones, and acute anterior uveitis (AAU) was significantly more frequent in HLA-B27 positive patients without differences in number of AAU episodes lifelong. Finally, obesity and concomitant fibromyalgia were both more common in HLA-B27 negatives. No significant differences were found for the rest of variables evaluated.

In the multivariate analysis, age at disease onset (OR 0.96, CI95\% 0.94-0.98), disease duration (OR 0.96, Cl95\% 0.92-0.99), PsA (OR 0.28, Cl95\% 0.09-0.85) presence of psoriasis (OR $0.22, \mathrm{Cl} 95 \% 0.07-0.64$ ), IBD related arthritis (OR 0.03 , CI95\% 0.01-0.19), AAU (OR 3.63, CI95\% 1.22-11.9) and tarsitis (OR 2.61, $\mathrm{Cl} 95 \%$ 1.01-6.98) were the most important variables independently associated to HLA-B27 status. 
Conclusion: Presence of HLA-B27 in pSpA patients was associated to a higher axial and root joint involvement, an earlier disease onset and presence of AAU, but not to PSA, psoriasis and IBD that were higher in HLA-B27 negative patients.

Table 1.

\begin{tabular}{|c|c|c|c|c|c|}
\hline & \multicolumn{2}{|c|}{$\mathrm{HLA}-\mathrm{B} 27+(\mathrm{N}=118)$} & \multicolumn{2}{|c|}{ HLA-B27- $(\mathrm{N}=168)$} & \multirow[b]{2}{*}{$\mathrm{p}$} \\
\hline & $\mathrm{N} /$ mean & $\% / S D$ & $\mathrm{~N} /$ mean & $\% / S D$ & \\
\hline Obesity (BMI >30) & 14 & $11,9 \%$ & 44 & $26,3 \%$ & 0,003 \\
\hline Men & 65 & $55,1 \%$ & 83 & $49,4 \%$ & 0,344 \\
\hline Family history & 44 & $37,3 \%$ & 52 & $31,0 \%$ & 0,265 \\
\hline Axial involvement & 62 & $52,5 \%$ & 42 & $25,0 \%$ & $<0.001$ \\
\hline Radiographic sacroilitis & 30 & $28,3 \%$ & 25 & $16,8 \%$ & 0,029 \\
\hline Psoriathic arthritis & 23 & $19,5 \%$ & 112 & $72,6 \%$ & $<0.001$ \\
\hline Reactive arthritis & 5 & $4,2 \%$ & 3 & $1,8 \%$ & 0,229 \\
\hline IBD arthritis & 1 & $0,9 \%$ & 8 & $4,8 \%$ & 0,098 \\
\hline Mono/oligoarticular pattern & 59 & $54,6 \%$ & 76 & $51,0 \%$ & 0,566 \\
\hline Root joint involvement & 52 & $44,1 \%$ & 54 & $32,1 \%$ & 0,04 \\
\hline Tarsitis & 22 & $18,6 \%$ & 16 & $9,5 \%$ & 0,028 \\
\hline Enthesitis & 62 & $52,5 \%$ & 69 & $41,1 \%$ & 0,056 \\
\hline Dactylitis & 31 & $26,3 \%$ & 51 & $30,4 \%$ & 0,452 \\
\hline Peripheral structural damage & 9 & $7,6 \%$ & 41 & $24,4 \%$ & $<0.001$ \\
\hline Psoriasis & 21 & $17,8 \%$ & 125 & $74,4 \%$ & $<0.001$ \\
\hline AAU & 21 & $17,8 \%$ & 7 & $4,2 \%$ & $<0.001$ \\
\hline IBD & 2 & $1,7 \%$ & 13 & $7,7 \%$ & 0,039 \\
\hline Fibromyalgia & 15 & $13,2 \%$ & 43 & $26,7 \%$ & 0,008 \\
\hline Age (y) & 42,7 & 14,8 & 52,2 & 13,4 & $<0.001$ \\
\hline Age onset (y) & 33,9 & 13,7 & 38,3 & 14,5 & 0,013 \\
\hline Dx delay $(\mathrm{m})$ & 4,7 & 8,2 & 7,7 & 9,8 & 0,009 \\
\hline Disease duration (y) & 9,06 & 10,2 & 14,2 & 11,6 & $<0.001$ \\
\hline BASDAI & 3,9 & 2,2 & 4,4 & 2,4 & 0,06 \\
\hline CRP & 16,9 & 25,1 & 12 & 27,3 & 0,148 \\
\hline ASDAS-CRP & 2,7 & 1,2 & 2,7 & 1,1 & 0,876 \\
\hline AAU number of episodes & 6,8 & 8,4 & 2,1 & 1,7 & 0,265 \\
\hline
\end{tabular}

Disclosure of Interests: Marta Arévalo Speakers bureau: Abbvie, Nordic Pharma, Clementina López-Medina: None declared, Victoria Navarro-Compán: None declared, Mireia Moreno Speakers bureau: Abbvie, Novartis, UCB, Bristol and AMGEN, María LLop Vilaltella Speakers bureau: Novartis, Joan Calvet: None declared, Jordi Gratacos-Masmitja Speakers bureau: During the course of the year, I have received funding for courses and conferences or as an advisor and speaker from MSD, Pfizer, AbbVie, Janssen Cilag, Novartis, Celgene, and Lilly., Maxime Dougados: None declared

DOI: 10.1136/annrheumdis-2021-eular.965

\section{POS0243 WHAT DOES REMISSION IN AXIAL SPONDYLOARTHRITIS MEAN FOR CLINICIANS? AN EXPLORATORY STUDY OF 200 FRENCH RHEUMATOLOGISTS BASED ON A VIGNETTE EXERCISE INCLUDING 36 CASES AND PRIORITY RATINGS}

K. Aouad ${ }^{1}$, D. Wendling ${ }^{2}$, A. Baglin ${ }^{3}$, M. Breban ${ }^{4}$, S. Dadoun ${ }^{5,6}$, C. Hudry7, A. Moltót 8,9 , E. Pertuiset ${ }^{10}$, L. Gossec ${ }^{1}{ }^{1}$ Sorbonne University; AP-HP, Pitié Salpêtrière Hospital, Rheumatology Department, Paris, France; ${ }^{2}$ Besançon University Hospital, Rheumatology Department, Besançon, France; ${ }^{3}$ Novartis, Pharmaceutical, Ile de France, France; ${ }^{4}$ APHP, Ambroise Paré Hospital, Rheumatology Department, Boulogne, France; ${ }^{5}$ Private practice, Rheumatology, Paris, France; ${ }^{6} \mathrm{CeSOA}, \mathrm{MGEN}$ action sociale, Rheumatology, Paris, France; ${ }^{6} \mathrm{CeSOA}$, MGEN action sociale, Rheumatology, Paris, France; ${ }^{8}$ Cochin Hospital, APHP, Rheumatology Department, Paris, France; ${ }^{9}$ INSERM U-1153 (ECAMO), CRESS, Université de Paris, Rheumatology, Paris, France; ${ }^{10}$ Rene Dubos Hospital, Rheumatology Department, Pontoise, France

Background: Treat-to-target in axial spondyloarthritis (axSpA) aims to achieve and maintain clinical remission/inactive disease or alternatively, low disease activity [1]. However, there is no consensual definition of remission in axSpA: the T2T international task force has proposed Ankylosing Spondylitis Disease Activity Score (ASDAS) inactive disease, but this definition is not widely accepted $[1,2]$.

Objectives: To explore rheumatologists' perception of remission in axSpA, using vignette cases and a priority exercise.

Methods: A steering group of 7 rheumatologists designed a national cross-sectional survey during two face-to-face meetings in 2019-2020. The survey comprised 36 vignette cases: fixed elements included the clinical picture (34 year-old-male with confirmed axSpA, normal C-reactive protein (CRP), without synovitis, enthesitis, dactylitis or extra-articular manifestations) and there were 3 varying parameters (axial pain (0-10) [ranging 2 to 5], fatigue (0-10) [2 to 8], and morning stiffness [ $<15$ minutes, 30 minutes or 1 hour]. For each vignette, the rheumatologist answered binarily: "do you consider this patient in remission: yes/ no". The second part of the survey comprised a priority rating (0-10 priority and 4 top items) of elements important to consider for remission, from a list of 12 items (BASDAI, ASDAS, elements of BASDAI and ASDAS including CRP, NSAIDs use, extra-articular manifestations, and other explanations for the symptoms e.g. fibromyalgia). The analysis was descriptive.

Results: Overall, 200 French rheumatologists participated between June and September 2020. Out of 2,400 vignette evaluations (mean of 66 evaluations per vignette), 463 (19\%) were classified as remission by rheumatologists. Six vignette cases constituted $56 \%$ of all remission cases (Figure 1): these comprised a short duration of morning stiffness ( $<15$ minutes), a low VAS axial pain (2 or 3) but with varying levels of VAS fatigue. When the duration of morning stiffness increased from 15 to 30 minutes and VAS axial pain increased from 2-3 to $4-5$ independently, classification as remission decreased from $42 \%$ to $12 \%$ and from $28-33 \%$ to $5-11 \%$, respectively. However, when VAS fatigue increased, it impacted less remission.

In priority ratings, 4 items were selected as important by $68-75 \%$ of rheumatologists: morning stiffness and axial pain (both included in the vignettes), as well as extra-articular manifestations and NSAID use, whereas only $18 \%$ selected fatigue. BASDAI was cited as the 1st priority criteria by $24 \%$ of rheumatologists and ASDAS as the $2^{\text {nd }}$ by $16 \%$ of rheumatologists.

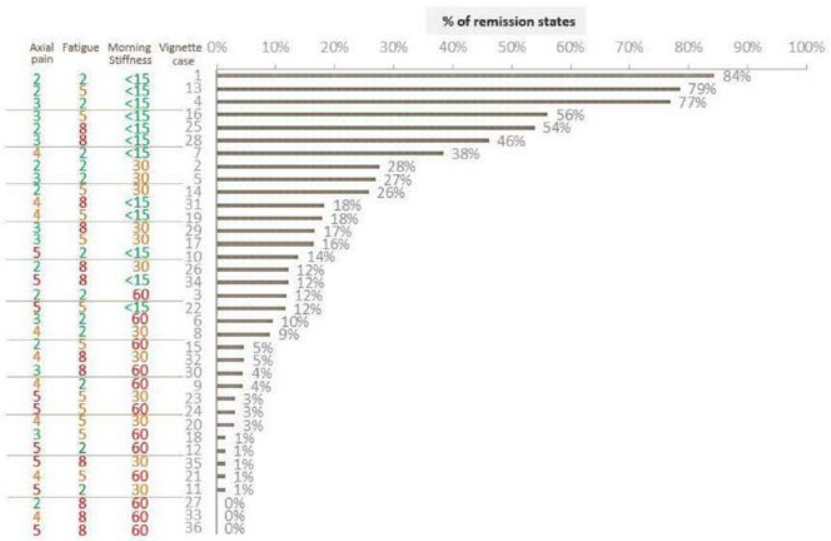

Figure 1. Frequencies of the declared remission states by rheumatologists for each of the 36 vignette cases

Conclusion: Morning stiffness, axial pain, NSAIDs use, and extra-articular manifestations seem to impact the physicians' perception of remission in axSpA whereas fatigue has less impact on remission for rheumatologists. Consensus is needed on remission in axSpA.

References: [1Smolen JS et al. Treating axial spondyloarthritis and peripheral spondyloarthritis, especially psoriatic arthritis, to target: 2017 update of recommendations by an international task force. Ann Rheum Dis 2018:77:3-17.

[2] Wendling D et al. 2018 update of French Society for Rheumatology (SFR) recommendations about the everyday management of patients with spondyloarthritis. Joint Bone Spine 2018;85:275-84.

Funding: This study was funded and organized by Novartis France Disclosure of Interests: Krystel Aouad: None declared, Daniel Wendling: None declared, Anne BAGLIN Employee of: Novartis, Maxime Breban: None declared, sabrina DADOUN: None declared, Christophe Hudry: None declared, Anna Moltó: None declared, Edouard Pertuiset: None declared, Laure Gossec: None declared

DOI: 10.1136/annrheumdis-2021-eular.1019

\section{POS0244 PATIENT JOURNEY WITH AXIAL SPONDYLOARTHRITIS: CRITICAL ISSUES FROM THE PATIENT PERSPECTIVE. RESULTS FROM THE EUROPEAN MAP OF AXIAL SPONDYLOARTHRITIS (EMAS)}

M. Garrido-Cumbrera ${ }^{1}$, D. Poddubnyy ${ }^{2}$, C. Bundy ${ }^{3}$, L. Christen ${ }^{4}$, R. Mahapatra ${ }^{5}$, S. Makri', C. J. Delgado-Domínguez ${ }^{1}$, S. Sanz-Gómez ${ }^{1}$, P. Plazuelo-Ramos ${ }^{7}$, V. Navarro-Compán ${ }^{8}$ on behalf of IMAS working group. ${ }^{1}$ Universidad de Sevilla, Health \& Territory Research (HTR), Seville, Spain; ${ }^{2}$ Charité - Universitätsmedizin Berlin, Rheumatology Department, Berlin, Germany; ${ }^{3}$ Cardiff University, School of Healthcare Sciences, Cardiff, United Kingdom; ${ }^{4}$ Novartis Pharma AG, Patient Engagement, Basel, Switzerland; ${ }^{5}$ Axial Spondyloarthritis International Federation (ASIF), Patient Advocacy, London, United Kingdom; ${ }^{6}$ Cyprus League Against Rheumatism (CYPLAR), Patient Advocacy, Nicosia, Cyprus; ${ }^{7}$ Spanish Federation of Spondyloarthritis Associations (CEADE), Presidency, Madrid, Spain; ${ }^{8}$ Hospital Universitario La Paz, IdiPaz, Madrid, Spain 